\title{
Social workers' determination of when children's access or potential access to loaded firearms constitutes child neglect
}

\author{
Charles A. Jennissen ${ }^{1 *}$, Erin M. Evans ${ }^{1}$, Alycia A. Karsjens ${ }^{2}$ and Gerene M. Denning ${ }^{1}$ \\ From 23rd Annual Injury Free Coalition for Kids Conference \\ Fort Lauderdale, FL, USA. 30 November - 2 December 2018
}

\begin{abstract}
Background: Pediatric firearm-related deaths and injuries are a serious societal problem. Our study's objective was to determine social workers' assessment of child neglect with respect to access or potential access to a loaded firearm.

Methods: Study invitations were delivered by e-mail to National Association of Social Workers members designating their practice as "Child/Family Welfare" ( $N=4933)$ in October/November, 2015. Demographics, attitudes regarding child access prevention (CAP) laws, and the ages (4-14 years) at which social workers deemed several scenarios as child neglect were determined. Descriptive (frequencies) and bivariate (chi square) analyses were performed.

Results: 485 of 4933 social workers completed the survey (9.8\%). Of these, most agreed or strongly agreed ( $\geq 92 \%)$ there should be laws in place requiring firearms to be stored so unwanted access cannot be obtained by a child, even up to 15 years of age. In a scenario where a child had potential access to a loaded firearm, but never gained access, the presence of a CAP law pertinent to the child in the scenario increased the likelihood respondents would find the situation child neglect for all ages ( $p<0.0001$ for each age comparison). Moreover, $10.3 \%$ felt they could not deem the situation child neglect without the presence of a CAP law, no matter the age of the child. In a scenario where a child gained access to a loaded firearm, the vast majority found this to be child neglect (82-99\%, with the percentage varying by the age of the child involved), regardless of the presence or absence of a CAP law and/or an injury being sustained. In addition, when a CAP law was in place, social workers were more likely to find neglect if the child had sustained a firearm-related injury as well ( $p$ values ranged from $0.016-0.0081$ for age comparisons).

Conclusions: The vast majority of child/family welfare social workers surveyed found it to be child neglect when youth accessed or had potential access to a loaded, unsecured firearm. Results of the study provide support for the passage of universal CAP laws to help protect children equally across states and ensure the safe storage of firearms in homes.
\end{abstract}

Keywords: Firearms, Child neglect, Gun storage, Child access prevention laws, Suicide, Social worker

\section{Background}

Firearm-related injury is one of the top three causes of pediatric deaths in the U.S (Dowd \& Sege, 2012; National Center for Injury Prevention and Control, 2018), and the country's youth mortality rate due to firearms is the highest in the world (Centers for Disease Control and Prevention, 1997; Grinshteyn \& Hemenway,

\footnotetext{
* Correspondence: charles-jennissen@uiowa.edu

'Department of Emergency Medicine, Roy J. and Lucille A. Carver College of Medicine, University of lowa, 200 Hawkins Drive, lowa City, IA 52242, USA

Full list of author information is available at the end of the article
}

2016). Although aggression with firearms remains a big problem, especially among older teens (Srinivasan et al., 2014; Teplin et al., 2014), most firearm-related hospitalizations and many deaths in children are not a result of assault or homicide (Srinivasan et al., 2014; Kalesan et al., 2016a; Kalesan et al., 2016b; Monuteaux et al., 2016; Tseng et al., 2018). Several national studies have found that over three-fifths of hospitalizations due to firearms in children < 16 years of age were not

(c) The Author(s). 2019 Open Access This article is distributed under the terms of the Creative Commons Attribution 4.0 International License (http://creativecommons.org/licenses/by/4.0/), which permits unrestricted use, distribution, and 
assault-related (Kalesan et al., 2016b; Tseng et al., 2018; Hamilton et al., 2018a).

Suicide is the second leading cause of death in the U.S. for 10-19 year olds (National Center for Injury Prevention and Control, 2016). In fact, the suicide rate for 15-19 year old males increased by nearly one-third from 2007 to 2015, while the rate for females more than doubled (Centers for Disease Control and Injury Prevention, 2017). Firearms play a major role, as $42 \%$ of completed teen suicides are executed with firearms (Shenassa et al., 2003). Suicidal ideation in youth can be impulsive, and the urge to commit suicide may be fleeting (Simon et al., 2001; Seiden, 1977). Unfortunately, firearms provide a swift method that is among the most deadly, having a $90 \%$ mortality rate (Elnour \& Harrison, 2008). Evidence is highly conclusive that firearm access in the home increases the risk of suicide (Grossman et al., 2005; Rivara, 2015; Dahlberg et al., 2004; Miller et al., 2013; Miller et al., 2007; Kung et al., 2005; Hemenway, 2011; Anglemyer et al., 2014; Stroebe, 2013).

Unintentional shootings are a significant cause of firearm-related injuries in children (Srinivasan et al., 2014; Kalesan et al., 2016a; Monuteaux et al., 2016). The majority of firearm-related hospital admissions for youth less than 15 years of age are due to unintentional injuries (Tseng et al., 2018; Hamilton et al., 2018a; Herrin et al., 2018). Approximately one-third of homes in the U.S. with children have one or more firearms (Johnson et al., 2004; Schuster et al., 2000; Hamilton et al., 2018b; Azrael et al., 2018), and they are frequently left loaded and unlocked where they are accessible to children (Schuster et al., 2000; Stennies et al., 1999). More than three-fourths of unintentional shootings occur in the home (Li et al., 1996; Faulkenberry \& Schaechter, 2015). In the majority of unintentional firearm-related injuries in children, the individual who pulled the trigger was a minor (Faulkenberry \& Schaechter, 2015; Eber et al., 2004; Grossman et al., 1999; Hemenway \& Solnick, 2015). One study found that the victim unintentionally shot themselves in one-third of the cases, and approximately half the time they were shot by a friend or member of the family ( $\mathrm{Li}$ et al., 1996). Securely storing all firearms to prevent their accessibility is associated with a reduction in unintentional firearm deaths in children, even after adjusting for firearm prevalence (Miller et al., 2005).

One approach to modify firearm safety-related attitudes and behaviors would be to apprise parents and legal guardians that improper firearm storage is considered child neglect by society, and could trigger investigation and action by child protective services. A survey of American Academy of Pediatrics (AAP) Section on Child Abuse and Neglect (SOCAN) members examined their attitudes about determining child neglect if an unsecured, loaded firearm was potentially accessed or accessed by children aged 4-14 years old. Even without an injury occurring or a strict child access prevention (CAP) law being present, the majority considered both a child's potential (range 90-67\% for children 4-14 years of age) and actual (range 100-88\% for children 4-14 years of age) access to an unsecured, loaded firearm as being child neglect (Evans et al., 2017a). However, it is unclear if social workers, including those who work or have worked as child protective service investigators, would be similar in this assessment.

In order to address this issue, we surveyed members of the National Association of Social Workers (NASW). The survey was constructed to better understand how social workers appraised situations involving children's potential or actual access to loaded firearms and under what circumstances they would determine the presence of child neglect. In addition, the study evaluated social workers' attitudes regarding the need for CAP laws for children of different ages.

\section{Methods \\ Survey development and validation}

The research team developed the survey tool and performed a pilot test with ten child welfare social workers to validate the survey as previously described (Jennissen et al., 2018). The University of Iowa and NASW Institutional Review Boards approved this study.

\section{Survey participants}

The NASW approved the e-mail distribution of the survey invitation to their members through INFOCUS ${ }^{\circ}$ Marketing, Inc., which is a firm that provides services to help organizations financially benefit by mail and e-mail marketing of products or services to their members. Survey distribution and data collection occurred from October to December 2015. Potential survey participants were NASW members who stated their practice fell into the category of "Child/Family Welfare." Study invitees were emailed messages with a link to an online survey available on REDCap, a secure web application for survey research and database management.

At the time of the study, there were 13 states that had more than 200 NASW members whose practice was child/family welfare, and, a randomized sample of 200 child welfare social workers from these states were invited to participate. For states with $<200$ NASW members, all members were e-mailed invitations. An e-mail reminder to complete the survey was sent 2-weeks after the first.

A total of 5719 survey invitations were sent with 4933 (86\%) deliverable in the first round of e-mails and 4570 $(80 \%)$ in the second. Of those that had deliverable emails, 1235 (25\%) and 1019 (22\%) were opened in the 
first and second round of e-mails, respectively. The marketing agency states that their average open rates for e-mail campaigns are 5-8\%. A total of 485 participated in the survey. This was $9.8 \%$ of all social workers that were delivered at least one invitation. The response rate considering only those that had opened up at least one e-mail invitation would be appreciably higher and range between $22 \%-39 \%$, but the exact denominator for this calculation cannot be determined.

Demographic variables for non-respondents could not be obtained from INFOCUS ${ }^{\circ}$ Marketing. Thus, demographic variables of all who were sent an e-mail survey invitation were utilized to compare against survey respondents.

\section{Subject-related variables}

Study demographic variables included sex, age, race/ethnicity, degree type, and whether the respondent was or had been a parent or child guardian. Subjects were also asked if they were presently or ever had been an investigator of child abuse/neglect for a government agency, lived in a household that owned a firearm, or had personally discharged a firearm. Those that had been a child protection investigator were asked the number of years they served in that capacity, as well as how many firearm-related cases they had investigated and the number of these cases that were eventually classified as founded. Geographic variables were the state (combined into four geographic regions), zip code in which they worked, and the population served (urban, suburban, rural). The rurality of the participant's workplace was determined using the Rural Urban Commuting Area (RUCA) codes (http://depts.washington.edu/uwruca/ ruca-approx.php) and classified as urban, large rural, small rural and isolated rural. For analysis, the three rural categories were combined.

\section{Attitudes regarding the need for CAP Laws}

Respondents were asked to provide a value using a 5-point Likert scale (Strongly Agree, Agree, Neutral, Disagree, Strongly Disagree) to indicate their level of agreement to the following statement, 'There should be a law requiring firearms to be safely stored (including separately stored ammunition) so that unwanted access to a loaded firearm cannot be gained by a child ...' Three ensuing conditions were provided with the child's age being $\leq 11, \leq 13$, and $\leq 15$ years old, respectively.

\section{Firearms scenarios}

Table 1 provides the scenarios used in the survey. Participants were told to ignore their state's laws and to answer questions based solely on their own judgment. In addition, they were advised that the child in the scenarios was physically and developmentally normal, with no behavioral problems. Finally, subjects were instructed to put a checkmark beside each age for which they believed the scenario constituted child neglect with the selections being $4,6,8,10,12$, and 14 years old.

\section{Data analysis}

SPSS (IBM Statistics Package for the Social Sciences, v22) was used to perform descriptive (frequencies) and bivariate (chi square) analyses. All $\mathrm{p}$ values were two-tailed with $\mathrm{p}<0.05$ defined as being significant.

Table 1 Firearms Scenarios from the NASW Child Neglect Survey ${ }^{a}$

Scenario 1: No firearm access by a child

A man becomes aware that his neighbors store a LOADED firearm in an unlocked drawer where their child could easily gain access to it. He alerts the police. The parents were aware that the firearm was stored in an unlocked drawer.

1A: Assume NO state laws were violated in this scenario. Is this child neglect if the child never touched the firearm and was 4, 6, 8, 10, 12, or 14 years old.

1B: Assume the child never touched the firearm, but state law requires firearms to be safely stored so a child of this age cannot gain access. Is this child neglect, if the child was 4, 6, 8, 10,12, or 14 years old.

Scenario 2: Firearm access by a child

A woman notices a child in the yard next door with a firearm. She alerts the police who quickly respond and confirm that the child had a loaded firearm. The parents were inside the house at the time. They were aware that they had stored a loaded firearm in an unlocked drawer.

2A: Assume NO state laws were violated in this scenario. Is this child neglect, if the child was uninjured and was 4, 6, 8, 10, 12, or 14 years old.

2B: Assume NO state laws were violated, but the child discharged the weapon causing a serious gunshot wound to the leg. Is this child neglect, if the child was 4, 6, 8,10,12, or 14 years old.

2C: Now assume that the child was NOT injured, but state law requires firearms to be safely stored so a child of this age cannot gain access. Is this child neglect, if the child was 4, 6, 8, 10, 12, or 14 years old.

2D: Assume the same state law as above was violated, AND the child discharged the weapon causing a serious gunshot wound to the leg. Is this child neglect, if the child was 4, 6, 8, 10, 12, or 14 years old. 


\section{Results}

\section{Respondent demographics}

Surveys were completed by 485 of 4933 NASW members practicing in Child/Family Welfare who had received the survey invitation by e-mail (9.8\%). Demographics of the respondents and comparison with corresponding data for all those having been sent a survey invitation (All Study Invitees) are shown in Table 2. The geographic region with the highest proportion of participants was the South, this proportion was higher than the percentage of NASW members from the South that were sent an e-mail to participate in the study (i.e. study invitees), $\mathrm{p}=0.026$. Respondents also had a higher proportion from the Midwest.

Females were $80 \%$ of survey respondents; a proportion not significantly different from invitees, $p=0.09$. Around $40 \%$ of respondents were $40-59$ years of age, a

Table 2 Comparison of demographics of survey respondents and all NASW Child/Family Welfare members who were sent an email inviting them to participate in the study ${ }^{a}$

\begin{tabular}{|c|c|c|c|}
\hline & $\begin{array}{l}\text { Study } \\
\text { Respondents } \\
\mathrm{N}=485 \\
\mathrm{n}(\mathrm{col} \%)^{\mathrm{b}}\end{array}$ & $\begin{array}{l}\text { All Study } \\
\text { Invitees } \\
\mathrm{N}=5719 \\
\mathrm{n}(\mathrm{col} \%)^{\mathrm{b}}\end{array}$ & $P$ value \\
\hline \multicolumn{4}{|l|}{ Region } \\
\hline Midwest & $118(26 \%)$ & $1341(23 \%)$ & \multirow[t]{4}{*}{0.026} \\
\hline Northeast & 85 (19\%) & 1214 (21\%) & \\
\hline South & 189 (41\%) & $2083(36 \%)$ & \\
\hline West & 67 (15\%) & 1081 (19\%) & \\
\hline \multicolumn{4}{|l|}{ Sex } \\
\hline Male & 78 (16\%) & 1044 (20\%) & \multirow[t]{2}{*}{0.09} \\
\hline Female & 401 (84\%) & 4292 (80\%) & \\
\hline \multicolumn{4}{|l|}{ Age (years old) } \\
\hline $20-39$ & 109 (23\%) & 1797 (32\%) & \multirow[t]{3}{*}{$<0.0001$} \\
\hline $40-59$ & 196 (41\%) & 1801 (32\%) & \\
\hline 60 and older & 169 (36\%) & 1965 (35\%) & \\
\hline \multicolumn{4}{|l|}{ Ethnicity } \\
\hline White/Caucasian & 362 (79\%) & 3846 (73\%) & \multirow[t]{4}{*}{$<0.0001$} \\
\hline $\begin{array}{l}\text { Black/African } \\
\text { American }\end{array}$ & $72(16 \%)$ & $823(16 \%)$ & \\
\hline Hispanic/Latino & $12(3 \%)$ & $314(6 \%)$ & \\
\hline Other ${ }^{r}$ & $10(2 \%)$ & $293(6 \%)$ & \\
\hline \multicolumn{4}{|l|}{ Degree } \\
\hline BSW & $46(10 \%)$ & $600(10 \%)$ & \multirow[t]{4}{*}{0.0006} \\
\hline MSW & $376(78 \%)$ & 4139 (72\%) & \\
\hline DSW & $24(5 \%)$ & $191(3 \%)$ & \\
\hline Other & $38(8 \%)$ & 789 (14\%) & \\
\hline
\end{tabular}

${ }^{a}$ Abbreviations: BSW Bachelors of Social Work, MSW Masters of Social Work, DSW Doctorate in Social Work

${ }^{\mathrm{b}}$ Column total $\mathrm{n}$ may not equal $\mathrm{N}$ due to missing data

'Other ethnicities include Asian, Pacific Islander, American Indian, and Native Alaskan significantly higher proportion than study invitees in this age range, $p<0.001$. As compared to invitees, survey participants had a higher proportion of White/Caucasians and lower proportions of Hispanic/ Latinos, and other ethnicities, $p<0.0001$. Seventy-eight percent had a Masters in Social Work, a proportion higher than that of study invitees as a whole, $p=0.0006$. The survey participants also had a higher proportion of doctorate degrees than study invitees.

Although $93 \%$ of respondents reported that their workplace was in an urban area, $41 \%$ indicated they primarily served rural populations (Table 3). Almost $70 \%$ of participants were parents or guardians. Nearly one-third stated someone in their household owned a firearm. Slightly less than half reported they had personally used a firearm. Forty-three percent indicated they were or had been an investigator, with nearly two-fifths having investigated one or more reported cases of potential child neglect related to a child having accessed a firearm. Of those investigators, $80 \%$ had found one or more of the cases investigated to be child neglect.

\section{Attitudes toward CAP Laws}

The vast majority of social workers in the study stated they "Agree" or "Strongly Agree" ( $\geq 92 \%)$ that there should be state laws requiring the safe storage of firearms in order to prevent children from accessing them, even if the child was 15 years of age. In fact, the percentages who stated they "Strongly Agree" with the need for strict CAP laws were 90\% (387/430), 85\% (368/434) and $81 \%(352 / 435)$ for children up to 11,13 , and 15 years of age, respectively.

There were some differences that were statistically significant following comparative analysis of reported attitudes. For example, males less commonly agreed that CAP laws were needed covering ages 11 and 13 years. Participants in households with firearms or who had used a firearm also less commonly agreed than their peers. However, the total number who disagreed in every case where there were differences was very small $(\leq 11)$.

\section{Results for Scenario 1}

In Scenario 1, a child had potential, but not actual access to a loaded and unlocked firearm. The majority of social workers who participated in the study found that the scenario constituted child neglect. Figure 1 shows the proportion of respondents who considered the scenario child neglect at the indicated age in the absence (No Law) and presence (Law) of a state CAP law. For each age, a significantly higher proportion of respondents made the determination of child neglect if there was a state law than when there was not, $p<0.0001$ for all ages. In the absence of a CAP law, 20.2\% (92/456) of participants indicated that they would not consider it 
Table 3 Other demographics of NASW Child/Family Welfare survey respondents. $\mathrm{N}=485$

\begin{tabular}{|c|c|}
\hline & $\mathrm{n}(\mathrm{col} \%)^{\mathrm{a}}$ \\
\hline \multicolumn{2}{|l|}{ Where They Work } \\
\hline Urban & $431(93 \%)$ \\
\hline Rural & $33(7 \%)$ \\
\hline \multicolumn{2}{|l|}{ Population Served } \\
\hline Urban & $146(32 \%)$ \\
\hline Suburban & $126(27 \%)$ \\
\hline Rural & $189(41 \%)$ \\
\hline \multicolumn{2}{|l|}{ Parent/Guardian } \\
\hline Yes & $330(69 \%)$ \\
\hline No & $149(31 \%)$ \\
\hline \multicolumn{2}{|c|}{ Household Owns Firearm } \\
\hline True & $139(32 \%)$ \\
\hline False & $289(68 \%)$ \\
\hline \multicolumn{2}{|l|}{ Have Used a Firearm } \\
\hline True & $202(47 \%)$ \\
\hline False & $226(53 \%)$ \\
\hline \multicolumn{2}{|c|}{ Are/Was an Investigator } \\
\hline Yes & $207(43 \%)$ \\
\hline No & $274(57 \%)$ \\
\hline \multicolumn{2}{|l|}{ Years as Investigator } \\
\hline Not investigator & $274(57 \%)$ \\
\hline$<6$ & $97(20 \%)$ \\
\hline 6 or more & $107(22 \%)$ \\
\hline \multicolumn{2}{|c|}{ Number of Cases Investigated ${ }^{b}$} \\
\hline None & $108(62 \%)$ \\
\hline $1-25$ & $57(33 \%)$ \\
\hline $26-100$ & $7(4 \%)$ \\
\hline$>100$ & $3(2 \%)$ \\
\hline \multicolumn{2}{|c|}{ Number of Cases Founded ${ }^{c}$} \\
\hline None & $12(20 \%)$ \\
\hline $1-25$ & $44(75 \%)$ \\
\hline $26-100$ & $2(3 \%)$ \\
\hline$>100$ & $1(2 \%)$ \\
\hline
\end{tabular}

${ }^{a}$ Column total $\mathrm{n}$ may not equal $\mathrm{N}$ due to missing data

${ }^{b}$ Number of cases investigated regarding children having access to a firearm by respondents who indicated they are or were an investigator of child abuse/neglect ${ }^{\mathrm{C}}$ Number of cases among those investigated regarding children having access to a firearm that were found to constitute child neglect

child neglect for any of the ages listed, including 4 years old. This was true for $9.2 \%(42 / 456)$ of participants when a CAP law was included in the scenario. These participants in each case were a significant contributor to observed differences. When this group was excluded from comparisons, significance was still reached when comparing maximum ages of 12 years old $(p=0.006)$ and 14 years old $(p=0.0008)$ with and without a law.
A comparison was performed between the 92 participants who did not regard Scenario 1A (no strict CAP law) to be child neglect for any of the ages listed, and all other respondents. Observed differences are summarized in Table 4. Relative to other respondents, the group that answered no age was child neglect had a higher proportion of males, of respondents serving rural communities, of persons living in households that owned a firearm, and of persons that had fired a gun. This group also had lower proportions that agreed with the need to have a CAP law covering 11 ( $84 \%$ vs. 99\%), 13 (85\% vs. 96\%), and $15(80 \%$ vs. $94 \%)$ year olds, $p<0.001$ in each case.

\section{Results for Scenario 2}

Scenario 2 involved a child who had accessed a loaded gun that was unsecured in the home under conditions where there was or was not a state CAP law and where the child did or did not sustain an injury. The vast majority of social worker respondents considered the scenario child neglect for all ages included in the study (4-14 years). In the absence of an injury (Fig. 2a), there were no differences in the age curves between scenarios with and without a CAP law. Similarly, in the absence of a law (Fig. 2b) there were no differences in the age curves between scenarios with and without an injury. If the child sustained an injury in the scenario (Fig. 2c), a significantly greater percentage considered the situation child neglect when a CAP law was also present as compared to when it was not for 14 year olds. With a CAP law (Fig. 2d), significantly greater proportions determined the situation child neglect when an injury had also been sustained as compared to when there was no injury for all ages. Figure 2e shows the most disparate situations in the scenario, no law/no injury versus law/ injury. In this case, significant differences were noted for ages 6 through 14 years.

\section{Discussion}

We found a strong consensus among social workers who work with children that allowing access or potential access to loaded firearms by children in the home constitutes child neglect. However, one of the factors that affected social worker determinations was the presence of a state CAP law. This was especially true in the scenario where the child had potential access to a loaded firearm; a finding that was previously noted in the determination of child neglect by surveyed child abuse and neglect experts (Evans et al., 2017a). In addition, social workers were significantly more likely to make the determination of child neglect after a child accessed a firearm when they suffered an injury as compared to when they had not if there was also a CAP law in place. Furthermore, and similar to what was found with child abuse and neglect experts (Evans et al., 2017a), almost all social 


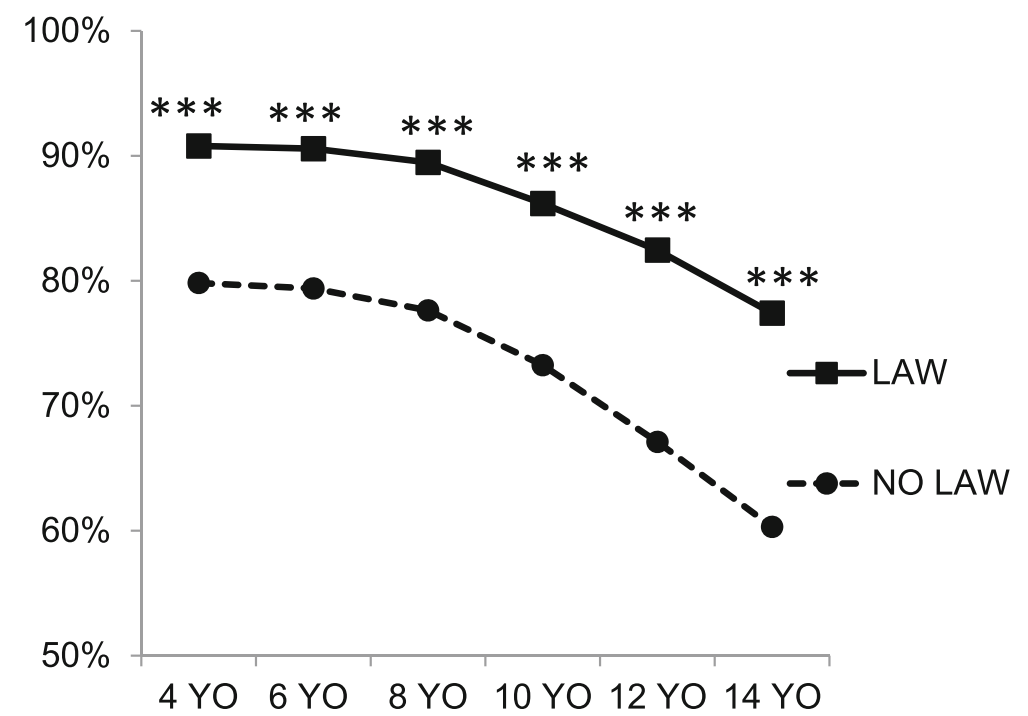

Fig. 1 A child has potential access to an unlocked, loaded firearm. The graph compares the proportion of survey respondents who considered Scenario 1 as child neglect for the indicated ages in the absence (NO LAW) or presence (LAW) of a CAP law. Asterisks $\left(^{*}\right)$ indicate statistically significant differences for pairwise comparisons: ${ }^{* *}, p<0.0001$

worker respondents affirmed that there should be CAP laws requiring firearms to be safely stored, including separately stored ammunition, to prevent unwanted access to a loaded firearm by children up through 15 years of age.

The majority of studies have found CAP laws to be associated with decreased rates of suicides and unintentional firearm injuries and deaths among children (Hamilton et al., 2018a; Santaella-Tenorio et al., 2016; Cummings et al., 1997; Webster et al., 2004; DeSimone et al., 2013; Webster \& Starnes, 2000; Lee et al., 2013; Hepburn et al., 2006). A case-control study showed that youth in homes with safer firearm storage had lower risks of both self-inflicted and unintentional firearm-related injuries (Grossman et al., 2005). Moreover, an analysis of the national Healthcare Cost and Utilization Project-Kids' Inpatient Database demonstrated strong CAP laws that imposed criminal liability for negligently stored firearms were associated with a $54 \%$ reduction in suicidal firearm-related injuries and a $44 \%$ reduction in unintentional injuries in children under 18 years as compared with states with no CAP law (Hamilton et al., 2018a). States with weak CAP laws showed no improvement over states with no CAP laws in the study. In addition, states with both CAP laws and stricter firearm legislation have been found to have lower rates of firearm ownership in households with young children, as well as safer storage of firearms in homes that do (Prickett et al., 2014). Encouraging safe storage, including the passage of strong CAP laws, may be as or even more effective than controlling sales in decreasing the mortality and morbidity risks of firearms in the home (Hamilton et al., 2018b).
The vast majority of social workers in the study determined a case as being child neglect when a youth had obtained an unsecured, loaded firearm in the home. The percentages of survey respondents finding child neglect decreased as child age increased in the scenario, mostly when children were 12 years of age and older. However, even when the child was 14 years of age, at least $82 \%$ of the social workers believed the circumstance as being child neglect. In a previous survey, child abuse and neglect experts had even higher percentages determining child neglect when evaluating identical scenarios of a child accessing an unlocked and loaded weapon in the home from that seen with the social workers in this study (Evans et al., 2017a).

In reality, parents often fail to take proper measures to ensure children are unable to come into the possession of household firearms. Of homes with children 17 years old and younger, 14-30\% have loaded firearms (Schuster et al., 2000; Azrael et al., 2000; Hemenway et al., 1995; Weil \& Hemenway, 1992). Among firearm-owning households with children, $43 \%$ have at least one firearm unlocked (Schuster et al., 2000), and 6-21\% have at least one firearm both unlocked and loaded (Schuster et al., 2000; Stennies et al., 1999; Azrael et al., 2000; Hemenway et al., 1995). Most parents assume their children would leave a firearm alone or tell an adult if they came across one (Connor \& Wesolowski, 2003; Farah et al., 1999), and many believe their child could be "trusted" with a loaded firearm (Farah et al., 1999).

However, these beliefs reveal a misconception of child and adolescent development, particularly regarding their curiosity and poor impulse control. A number of studies 
Table 4 Comparison of Social Workers with Differing Beliefs of Child Neglect Regarding a Child's Potential Access to a Loaded Firearm When No Cap Law is Present ${ }^{a}$

\begin{tabular}{|c|c|c|c|}
\hline & $\begin{array}{l}\text { No Child Neglect at Any Age } \\
\mathrm{n}(\mathrm{col} \%)^{\mathrm{b}}\end{array}$ & $\begin{array}{l}\text { Child Neglect for Some Ages } \\
\mathrm{n}(\mathrm{col} \%)^{\mathrm{b}}\end{array}$ & $p$ value \\
\hline Group N & 92 & 364 & \\
\hline \multicolumn{4}{|l|}{ Sex } \\
\hline Male & $22(24 \%)$ & $55(15 \%)$ & \multirow[t]{2}{*}{0.042} \\
\hline Female & $68(76 \%)$ & $307(85 \%)$ & \\
\hline \multicolumn{4}{|c|}{ Population Served } \\
\hline Urban & $22(25 \%)$ & 117 (34\%) & \multirow[t]{3}{*}{0.037} \\
\hline Suburban & $19(22 \%)$ & $97(28 \%)$ & \\
\hline Rural & $47(53 \%)$ & $133(38 \%)$ & \\
\hline \multicolumn{4}{|c|}{ Household Owns Firearms } \\
\hline True & $36(44 \%)$ & $103(30 \%)$ & \multirow[t]{2}{*}{0.018} \\
\hline False & $46(56 \%)$ & $241(70 \%)$ & \\
\hline \multicolumn{4}{|c|}{ Have Used a Firearm } \\
\hline True & $53(65 \%)$ & $149(43 \%)$ & \multirow[t]{2}{*}{$<0.001$} \\
\hline False & $28(35 \%)$ & $196(57 \%)$ & \\
\hline
\end{tabular}

"There should be a law requiring firearms be safely stored (including separately stored ammunition) so that unwanted access to a loaded firearm cannot be gained by a ....."

Child Age $\leq 11$

$\begin{array}{llll}\text { Strongly Agree } & 61(74 \%) & 324(94 \%) & 16(5 \%) \\ \text { Agree } & 8(10 \%) & 1(0.3 \%) & \%(1 \%) \\ \text { Neutral } & 6(7 \%) & 0(0 \%) \\ \text { Disagree } & 4(5 \%) & \\ \text { Strongly Disagree } & 3(4 \%) & 313(89 \%) \\ \text { Child Age } \leq 13 & & 26(7 \%) \\ \text { Strongly Agree } & 53(65 \%) & 5(1 \%) \\ \text { Agree } & 16(20 \%) & 5(1 \%) \\ \text { Neutral } & 5(6 \%) & 1(0.3 \%) \\ \text { Disagree } & 4(5 \%) & \\ \text { Strongly Disagree } & 4(5 \%) & 299(85 \%) \\ \text { Child Age } \leq 15 & & 32(9 \%) \\ \text { Strongly Agree } & 51(61 \%) & 7(2 \%) \\ \text { Agree } & 16(19 \%) & 11(3 \%) \\ \text { Neutral } & 8(10 \%) & 1(0.3 \%) \\ \text { Disagree } & 4(5 \%) & 4(5 \%) & <0.001 \\ \text { Strongly Disagree } & & \end{array}$

${ }^{a}$ Characteristics of a group who did not regard Scenario $1 \mathrm{~A}$ (potential child access to a loaded firearm with no strict CAP law) as being child neglect for any of the ages listed in the study, including 4 years of age, as compared to other survey respondents.

bColumn $\mathrm{n}$ total may not equal $\mathrm{N}$ due to missing data.

have demonstrated that most children, and especially males, will handle a weapon they encounter when not under direct adult supervision (Hardy, 2002; Hardy et al., 1996; Jackman et al., 2001). Nearly three-quarters of children 5-14 years of age in homes with firearms know where they are kept, and $36 \%$ have actually handled the weapon-contrary to their parents' expectations (Baxley \& Miller, 2006). Even three-year-olds can generate the pressure necessary to pull the trigger of $92.5 \%$ of the handguns in circulation (Naureckas et al., 1995). Although nearly all firearm owners believe that talking to youth about gun safety is essential (Parker et al., 2017), safety instruction does not alter the probability of a child handling a found firearm (Hardy, 2002; Hardy et al., 1996; Jackman et al., 2001). 


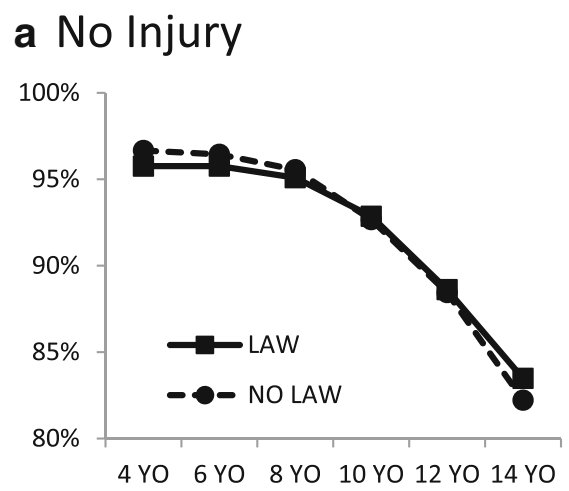

c Injury

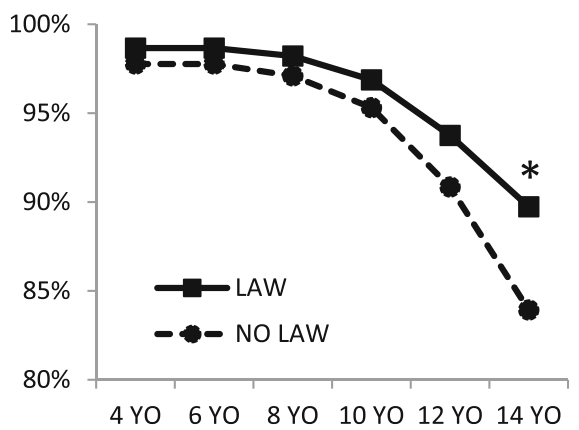

b No Law

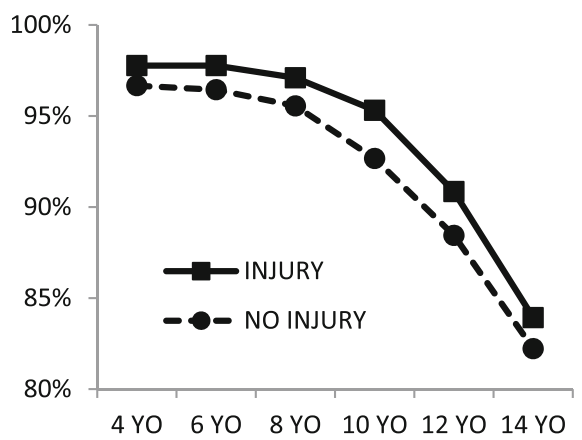

d Law

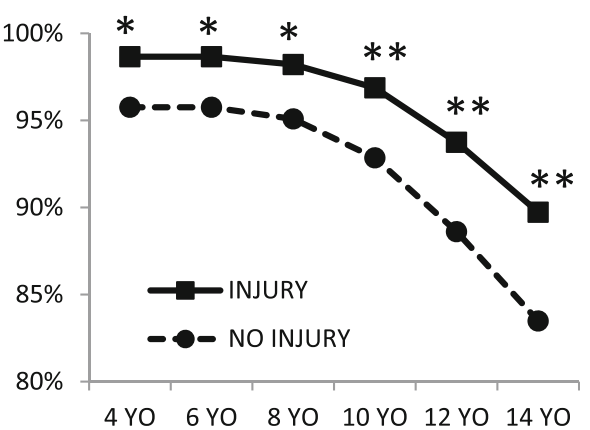

e Law/Injury vs. No Law/No Injury



Fig. 2 A child has gained access to an unlocked, loaded firearm. The graphs compare the proportion of survey respondents who considered Scenario 2 as child neglect for the indicated ages. a scenario where there was no injury to the child and in the absence (NO LAW) or presence (LAW) of a CAP law. b scenario where there was no CAP law and the child did (INJURY) or did not (NO INJURY) sustain an injury. c scenario where the child sustained an injury in the absence (NO LAW) or presence (LAW) of a CAP law. $\mathbf{d}$ scenario where there was a CAP law present and the child did (INJURY) or did not (NO INJURY) sustain an injury. e scenario for the most disparate conditions, i.e. absence of a CAP law and no injury to the child (NO LAW + NO INJURY) versus presence of a CAP law and injury to the child (LAW + INJURY). Asterisks $\left({ }^{*}\right)$ indicate statistically significant differences for pairwise comparisons: ${ }^{*}, p<0.05 ;{ }^{* *}, p<0.01$

The high prevalence of unsecure firearm storage and the discordance between parent's perceptions and how children actually behave reveal attitudes that are significant obstacles to achieving universal firearm safety in households with children. One way to potentially modify these attitudes and change behavior is to make parents and the public mindful of what experts believe constitutes child neglect with regards to firearms. More importantly, parents and other caregivers becoming cognizant that child protective services are investigating and finding child neglect when firearms are not properly secured from children may be a more effective deterrent.

The vast majority of surveyed social workers also found the situation child neglect when 4-14 year olds 
had potential access to an unlocked and loaded firearm, but the proportions significantly increased for all ages when a CAP law was present. In addition, more than half of social workers that did not regard potential access to a loaded firearm as child neglect at any age in the absence of a law reversed that decision if a CAP law was included in the scenario. Child neglect determinations should be based on risk assessment, and the risks are the same regardless of whether there's a CAP law. However, our results support the hypothesis that CAP laws make a difference not only in their potential direct effects on reducing pediatric firearm-related injuries and deaths, but also in how they may impact social worker's determinations of child neglect.

\section{Limitations}

Since only NASW members whose practice was child welfare were surveyed and our response rate was relatively low, the generalizability of the study may be limited. It is also possible that selection bias may have resulted from incomplete membership participation, and there were some differences in demographics between those that participated in the survey and non-respondents. However, the study results are very similar to that found with another group of experts in child neglect (Evans et al., 2017b). In addition, the participant's determination of child neglect was after consideration of a survey scenario; it is uncertain if respondent's actions would be similar or vary when evaluating actual cases. Despite limitations, this study addresses a significant knowledge gap as it is the first to assess social workers' opinions regarding firearm access and child neglect.

\section{Conclusions}

Of child/family welfare social workers who responded to our study, the vast majority determined that scenarios of children's potential and actual access of unsecured and loaded firearms represented child neglect. However, these determinations of neglect were affected in some cases by the presence of CAP laws. Additionally, the preponderance of social workers in the study strongly agreed that there should be strict CAP laws, even through 15 years of age. As CAP laws markedly vary between states and many have none, determinations of child neglect when children access or have potential access to firearms are likely inconsistent from state to state. This might be improved with passage of strict universal CAP laws. Additionally, parents and other caretakers being held accountable for child neglect when there is access or potential access to firearms in the home might provide a strong stimulus for properly storing firearms. Reducing childhood firearm access could in turn decrease intentional (including suicide) and unintentional firearm-related deaths and injuries.

\begin{abstract}
Abbreviations
AAP: American Academy of Pediatrics; BSW: Bachelors of Social Work; CAP: child access prevention; DSW: Doctorate of Social Work; MSW: Masters of Social Work; NASW: National Association of Social Workers; RUCA: Rural Urban Commuting Area; SOCAN: Section on Child Abuse and Neglect; SPSS: IBM Statistics Package for the Social Sciences
\end{abstract}

\section{Acknowledgements}

We would like to acknowledge the contribution of Resmiye Oral, MD, for her help work in developing the study survey.

\section{Funding \\ Support for this study was provided by The Department of Emergency Medicine at The University of lowa. Ms. Evans was supported by a research fellowship from the Carver College of Medicine Medical Student Summer Research Program. In addition, this work was funded in part by Institute for Clinical and Translational Science grant support (NIH/CTSA grant \#: U54TR001356). Publication costs are funded by the Injury Free Coalition for Kids ${ }^{\mathrm{TM}}$.}

\section{Availability of data and materials}

Data and materials are available to other parties for research purposes after a data sharing agreement plan is agreed to and signed.

\section{About this supplement \\ This article has been published as part of Injury Epidemiology Volume 6 Supplement 1, 2019: Proceedings from the 23rd Annual Injury Free Coalition for Kids ${ }^{\circledR}$ Conference: Forging New Frontiers: Pediatric Injury Prevention - Process, Programs and Progress. The full contents of the supplement are available online at https://injepijournal.biomedcentral.com/articles/supplements/ volume-6-supplement-1.}

\section{Author's contributions}

All authors have read and approved the final manuscript. Each author significantly contributed to and takes public responsibility for one or more aspects of the study. Specifically: CJ had primary responsibility for study design, survey development and validation, supervision of research students, and interpretation of the data. He also helped in writing the manuscript and had primary responsibility for its final form and submission. EE helped in development and validation of the survey and in entering and organizing survey results. She also helped in analysis and interpretation of the data and provided editorial comments on the manuscript. AK helped in development and validation of the survey, fielding and answering questions by e-mail from subjects and potential subjects, and provided editorial comments on the manuscript. GD helped with final analysis of the data and organization of the results. She also helped in interpretation of the data and in writing of the manuscript.

Ethics approval and consent to participate

The University of lowa and National Association of Social Workers (NASW) Institutional Review Boards approved this study.

\section{Consent for publication}

Research participants consented to participate in the survey and provided permission for their answers to be included in the publication of the results. 


\section{Publisher's Note}

Springer Nature remains neutral with regard to jurisdictional claims in published maps and institutional affiliations.

\section{Author details}

'Department of Emergency Medicine, Roy J. and Lucille A. Carver College of Medicine, University of lowa, 200 Hawkins Drive, lowa City, IA 52242, USA.

${ }^{2}$ Department of Social Service, University of lowa Hospitals and Clinics, lowa City, IA 52242, USA.

\section{Published: 29 May 2019}

\section{References}

Anglemyer A, Horvath T, Rutherford G. The accessibility of firearms and risk for suicide and homicide victimization among household members: a systematic review and meta-analysis. Ann Intern Med. 2014;160(2):101-10.

Azrael D, Cohen J, Salhi C, Miller M. Firearm storage in gun-owning households with children: results of a 2015 National Survey. J Urban Health. 2018;95(3):295-304.

Azrael D, Miller M, Hemenway D. Are household firearms stored safely? It depends on whom you ask. Pediatrics. 2000;106(3):E31.

Baxley F, Miller M. Parental misperceptions about children and firearms. Arch Pediatr Adolesc Med. 2006;160(5):542-7.

Centers for Disease Control and Injury Prevention. QuickStats: suicide rates for teens aged 15-19 Years, by sex — United States. MMWR (Morb. Mortal. Wkly. Rep.). 2017:66(30) (1975-2015)):816.

Centers for Disease Control and Prevention. Rates of homicide, suicide, and firearm-related deaths among children in 26 industrialized countries. MMWR Morb Mortal Wkly Rep. 1997;46:101-5.

Connor SM, Wesolowski KL. "They're too smart for that": predicting what children would do in the presence of guns. Pediatrics. 2003;111(2):E109-14.

Cummings P, Grossman DC, Rivara FP, Koepsell TD. State gun safe storage laws and child mortality due to firearms. JAMA. 1997;278(13):1084-6.

Dahlberg LL, Ikeda RM, Kresnow MJ. Guns in the home and risk of a violent death in the home: findings from a national study. Am J Epidemiol. 2004;160(10):929-36.

DeSimone J, Markowitz S, Xu J. Child access prevention laws and nonfatal gun injuries. South Econ J. 2013;80(1):5-25.

Dowd M, Sege R. Council on injury, violence, and poison prevention. American Academy of Pediatrics. Firearm-related injuries affecting the pediatric population. Pediatrics. 2012;130(5):e1416-23.

Eber GB, Annest JL, Mercy JA, Ryan GW. Nonfatal and fatal firearm-related injuries among children aged 14 years and younger: United States, 1993-2000. Pediatrics. 2004;113(6):1686-92.

Elnour AA, Harrison J. Lethality of suicide methods. Inj Prev. 2008;14(1):39-45.

Evans EM, Jennissen CA, Oral R, Denning GM. Child welfare professionals' determination of when children's access or potential access to loaded firearms constitutes child neglect. J Trauma Acute Care Surg. 2017a;83(5S Suppl 2):S210-S6

Evans EM, Jennissen CA, Oral R, Denning GM. Child welfare professionals' determination of when children's access or potential access to loaded firearms constitutes child neglect. J Trauma Acute Care Surg. 2017b;83(5S Suppl 2):S210-S6.

Farah MM, Simon HK, Kellermann AL. Firearms in the home: parental perceptions. Pediatrics. 1999;104(5 Pt 1):1059-63.

Faulkenberry JG, Schaechter J. Reporting on pediatric unintentional firearm injury--who's responsible. J Trauma Acute Care Surg. 2015;79(3 Suppl 1):S2-8.

Grinshteyn E, Hemenway D. Violent death rates: the US compared with other high-income OECD countries, 2010. Am J Med. 2016;129(3):266-73.

Grossman DC, Mueller BA, Riedy C, Dowd MD, Villaveces A, Prodzinski J, et al. Gun storage practices and risk of youth suicide and unintentional firearm injuries. JAMA. 2005;293(6):707-14.

Grossman DC, Reay DT, Baker SA. Self-inflicted and unintentional firearm injuries among children and adolescents: the source of the firearm. Arch Pediatr Adolesc Med. 1999;153(8):875-8.

Hamilton D, Lemeshow S, Saleska J, Brewer B, Strobino K. Who owns guns and how do they keep them? The influence of household characteristics on firearms ownership and storage practices in the United States. Prev Med. 2018b;116:134-42.

Hamilton EC, Miller CC 3rd, Cox CS Jr, Lally KP, Austin MT. Variability of child access prevention laws and pediatric firearm injuries. J Trauma Acute Care Surg. 2018a;84(4):613-9.
Hardy MS. Teaching firearm safety to children: failure of a program. J Dev Behav Pediatr. 2002;23(2):71-6.

Hardy MS, Armstrong FD, Martin BL, Strawn KN. A firearm safety program for children: they just can't say no. J Dev Behav Pediatr. 1996;17(4):216-21.

Hemenway D. Risks and benefits of a gun in the home. Am J Lifestyle Medicine. 2011:502-11.

Hemenway D, Solnick SJ. Children and unintentional firearm death. Inj Epidemiol. 2015;2(1):26.

Hemenway D, Solnick SJ, Azrael DR. Firearm training and storage. JAMA. 1995; 273(1):46-50.

Hepburn L, Azrael D, Miller M, Hemenway D. The effect of child access prevention laws on unintentional child firearm fatalities, 1979-2000. J Trauma. 2006;61(2):423-8.

Herrin B, Gaither J, Leventhal J, Dodington J. Rural versus urban hospitalizations for firearm injuries in children and adolescents. Pediatrics. 2018;142(2): e20173318.

Jackman GA, Farah MM, Kellermann AL, Simon HK. Seeing is believing: what do boys do when they find a real gun? Pediatrics. 2001;107(6):1247-50.

Jennissen C, Evans EM, Oral R, Denning G. Child abuse and neglect experts determination of when a child being left home alone constitutes child neglect. Injury Epidemiology. 2018;Accepted for Publication.

Johnson RM, Coyne-Beasley T, Runyan CW. Firearm ownership and storage practices, U.S. households, 1992-2002. A systematic review. Am J Prev Med. 2004;27(2):173-82.

Kalesan B, Dabic S, Vasan S, Stylianos S, Galea S. Racial/ethnic specific trends in pediatric firearm-related hospitalizations in the United States, 1998-2011. Matern Child Health J. 2016a;20(5):1082-90.

Kalesan B, Vyliparambil MA, Bogue E, Villarreal MD, Vasan S, Fagan J, et al. Race and ethnicity, neighborhood poverty and pediatric firearm hospitalizations in the United States. Ann Epidemiol. 2016b;26(1):1-6 e1-2.

Kung HC, Pearson JL, Wei R. Substance use, firearm availability, depressive symptoms, and mental health service utilization among white and African American suicide decedents aged 15 to 64 years. Ann Epidemiol. 2005;15(8):614-21.

Lee J, Moriarty KP, Tashjian DB, Patterson LA. Guns and states: pediatric firearm injury. J Trauma Acute Care Surg. 2013;75(1):50-3 discussion 3.

Li G, Baker SP, DiScala C, Fowler C, Ling J, Kelen GD. Factors associated with the intent of firearm-related injuries in pediatric trauma patients. Arch Pediatr Adolesc Med. 1996;150(11):1160-5.

Miller M, Azrael D, Hemenway D, Vriniotis M. Firearm storage practices and rates of unintentional firearm deaths in the United States. Accid Anal Prev. 2005;37(4):661-7.

Miller M, Barber C, White RA, Azrael D. Firearms and suicide in the United States: is risk independent of underlying suicidal behavior? Am J Epidemiol. 2013;178(6):946-55.

Miller M, Lippmann SJ, Azrael D, Hemenway D. Household firearm ownership and rates of suicide across the 50 United States. J Trauma. 2007;62(4):1029-34 discussion 34-5.

Monuteaux MC, Mannix R, Fleegler EW, Lee LK. Predictors and outcomes of pediatric firearm injuries treated in the emergency department: differences by mechanism of intent. Acad Emerg Med Off J Soc Acad Emerg Med. 2016;23(7):790-5.

National Center for Injury Prevention and Control. Injury Prevention \& Control: Data \& Statistics (WISQARS). Centers for Disease Control and Prevention, Atlanta, GA WISQARS Database. Available at: https://www.cdc.gov/injury/ wisqars/ Accessed 27 Oct 2016. 2016.

National Center for Injury Prevention and Control. Web-based Injury Statistics Query \& Reporting System (WISQARS) Fatal Injury Reports for National, Regional, and States, 1999-2016. Centers for Disease Control and Prevention, Atlanta, Georgia (2018). https://webappa.cdc.gov/sasweb/ncipc/mortrate.html Accessed 9/27/2018

Naureckas SM, Galanter C, Naureckas ET, Donovan M, Christoffel KK. Children's and women's ability to fire handguns. The pediatric practice research group. Arch Pediatr Adolesc Med. 1995;149(12):1318-22.

Parker K, Horowitz J, Igielnik R, Oliphant B, Brown A. America's complex relationship with guns: an in-depth look at the attitudes and experiences of U.S. adults. Pew Research Center. June 22, 2017. 2017.

Prickett KC, Martin-Storey A, Crosnoe R. State firearm laws, firearm ownership, and safety practices among families of preschool-aged children. Am J Public Health. 2014;104(6):1080-6. 
Rivara FP. Youth suicide and access to guns. JAMA Pediatr. 2015;169(5):429-30. Santaella-Tenorio J, Cerda M, Villaveces A, Galea S. What do we know about the association between firearm legislation and firearm-related injuries? Epidemiol Rev. 2016;38(1):140-57.

Schuster MA, Franke TM, Bastian AM, Sor S, Halfon N. Firearm storage patterns in US homes with children. Am J Public Health. 2000;90(4):588-94.

Seiden R. Suicide prevention: a public health/public policy approach. Omega (Westport). 1977;8:267-76.

Shenassa ED, Catlin SN, Buka SL. Lethality of firearms relative to other suicide methods: a population based study. J Epidemiol Community Health. 2003:57(2):120-4

Simon OR, Swann AC, Powell KE, Potter LB, Kresnow MJ, O'Carroll PW. Characteristics of impulsive suicide attempts and attempters. Suicide Life Threat Behav. 2001;32(1 Suppl):49-59.

Srinivasan S, Mannix R, Lee LK. Epidemiology of paediatric firearm injuries in the USA, 2001-2010. Arch Dis Child. 2014;99(4):331-5.

Stennies G, Ikeda R, Leadbetter S, Houston B, Sacks J. Firearm storage practices and children in the home, United States, 1994. Arch Pediatr Adolesc Med. 1999;153(6):586-90

Stroebe W. Firearm possession and violent death. Agress Violent Behav. 2013;18:709-21.

Teplin LA, Jakubowski JA, Abram KM, Olson ND, Stokes ML, Welty LJ. Firearm homicide and other causes of death in delinquents: a 16-year prospective study. Pediatrics. 2014;134(1):63-73.

Tseng J, Nuno M, Lewis AV, Srour M, Margulies DR, Alban RF. Firearm legislation, gun violence, and mortality in children and young adults: a retrospective cohort study of 27,566 children in the USA. Int J Surg. 2018;57:30-4.

Webster DW, Starnes M. Reexamining the association between child access prevention gun laws and unintentional shooting deaths of children. Pediatrics. 2000;106(6):1466-9.

Webster DW, Vernick JS, Zeoli AM, Manganello JA. Association between youthfocused firearm laws and youth suicides. JAMA. 2004;292(5):594-601.

Weil DS, Hemenway D. Loaded guns in the home. Analysis of a national random survey of gun owners. JAMA. 1992;267(22):3033-7.

Ready to submit your research? Choose BMC and benefit from:

- fast, convenient online submission

- thorough peer review by experienced researchers in your field

- rapid publication on acceptance

- support for research data, including large and complex data types

- gold Open Access which fosters wider collaboration and increased citations

- maximum visibility for your research: over $100 \mathrm{M}$ website views per year

At $\mathrm{BMC}$, research is always in progress.

Learn more biomedcentral.com/submissions 